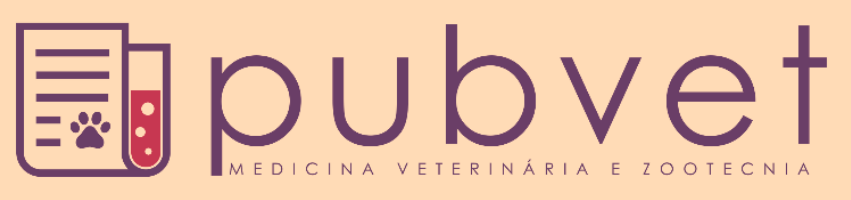

https://doi.org/10.31533/pubvet.v13n7a371.1-6

\title{
Confecção de modelo de baixo custo para treinamento de ressuscitação cardiopulmonar em cão
}

\author{
Flávia Thaysa Vieira Freitag ${ }^{1 *}$, Isabela Mello Mazepa $^{1} \bullet$, Gabriela Saidel Pereira ${ }^{1} \bullet$, Bruna Natali da \\ $\operatorname{Costa}^{2 \theta}$, Carolina Trochmann Cordeiro ${ }^{2} \theta$, Matheus Barbosa Gomes $\mathrm{Cruz}^{2 \theta}$, Simone Tostes de Oliveira ${ }^{3 \oplus}$ \\ ${ }^{1}$ Discente do curso de Medicina Veterinária da Universidade Federal do Paraná (UFPR), Curitiba-PR Brasil; \\ ${ }^{2}$ Discente no Programa de Pós-graduação em Ciências Veterinárias da Universidade Federal do Paraná (UFPR), Curitiba-PR Brasil; \\ ${ }^{3}$ Docente do Departamento de Medicina Veterinária, Universidade Federal do Paraná (UFPR). Curitiba -PR Brasil. \\ *Autor para correspondência, E-mail: flaviatufreitag@gmail.com
}

Resumo. A ressuscitação cardiopulmonar (RCP) deve ser iniciada prontamente em uma situação de parada cardiorrespiratória (PCR). O Reassessment Campaign on Veterinary Resuscitation (RECOVER) propõe recomendações clínicas para a aplicação do procedimento em cães e gatos e também reconhece a necessidade de habilidades cognitivas e psicomotoras para realizar todo o protocolo de maneira ágil e eficiente. Deste modo, um treinamento ideal deve abranger componentes didáticos e prática de habilidades manuais, com o uso de simuladores e modelos discriminados. A utilização de métodos alternativos com modelos sintéticos é sustentada pelas crescentes preocupações com o bem-estar animal, demanda que é apresentada por acadêmicos de Medicina Veterinária e residentes do Hospital Veterinário da Universidade Federal do Paraná. Somado ao alto custo de modelos já disponíveis comercialmente, o objetivo do presente trabalho é apresentar a confecção de um modelo de baixo custo para treinamento de RCP em cão. Após aquisição de um cão de pelúcia, foi elaborada uma estrutura representativa da parte interna do tórax com uma embalagem plástica de achocolatado em pó preenchida com fibra siliconada. Em seguida foram produzidas as cartilagens da laringe em borracha de silicone de média flexibilidade, aderidas a uma traqueia corrugada. Os moldes do palato duro e das arcadas dentárias superior e inferior foram confeccionados em resina, pintados com tinta acrílica e fixados a uma articuladora dental modificada. Para a mucosa oral e língua foram elaboradas estruturas de elastômero de silicone de baixa viscosidade. O modelo permitiu realizar os procedimentos de compressão torácica e intubação endotraqueal, etapas incluídas na RCP. O modelo foi testado por profissionais da Medicina Veterinária, com experiência em RCP, e foi relatado um bom resultado. O modelo de RCP apresentado permitiu a simulação do suporte básico à vida e, sendo de baixo custo, pode ser confeccionado por outras instituições de ensino com este mesmo propósito.

Palavras chave: compressão torácica, ensino, intubação endotraqueal, RCP, simulador

\section{Cost-effective model for cardiopulmonar ressucitation training in dogs}
Abstract. Cardiopulmonary resuscitation (CPR) should be started promptly in a situation of cardiorespiratory arrest (CRP). The Reassessment Campaign on Veterinary Resuscitation (RECOVER) proposes clinical recommendations for the application of the procedure in dogs and cats and also recognizes the need for cognitive and psychomotor skills to perform the entire protocol in an agile and efficient manner. In this way, an ideal training should cover didactic components and practice of manual skills, with the use of discriminated models and simulators. The use of alternative methods with synthetic models is supported by the increase in concerns about animal welfare, a demand that is presented by Veterinary Medicine scholars and residents of the Veterinary Hospital of the Federal 
University of Paraná (UFPR). In addition to the high cost of commercially available models, the objective of this work is to present a low-cost model for training CPR in dogs. After acquisition of a plush dog, a representative structure of the internal part of the chest was elaborated with a plastic packaging of powdered chocolate filled with silicon fiber. Then, the larynx cartilages were produced in silicone rubber of medium flexibility, adhered to a corrugated trachea. The molds of the hard palate and upper and lower dental arches were made of resin, painted with acrylic paint and fixed to a modified dental articulator. For the oral mucosa and tongue it was made low viscosity silicone elastomer structures. The model allowed to perform the procedures of thoracic compression and endotracheal intubation, steps included in the CPR. The model was tested by Veterinary Medicine professionals with experience in CPR, and a good result was reported. The presented CPR model allowed the simulation of the basic support to life and, being of low cost, can be made by other educational institutions with this same purpose.

Keywords: thoracic compression, teaching, endotracheal intubation, CPR, simulator

\section{Confección de modelo de bajo costo para entrenamiento de resucitación cardiopulmonar em caninos}

Resumen. La resucitación cardiopulmonar (RCP) debe iniciarse rápidamente en una situación de parada cardiorrespiratoria (PCR). La RECOVER (Reassessment Campaign on Veterinary Resuscitation) propone recomendaciones clínicas para la aplicación del procedimiento en caninos y felinos ou pequeños animales y también reconoce la necesidad de habilidades cognitivas y psicomotoras para realizar todo el protocolo de manera ágil y eficiente. De este modo, un entrenamiento ideal debe abarcar componentes didácticos y práctica de habilidades manuales, con el uso de simuladores y modelos discriminados. La utilización de métodos alternativos con modelos sintéticos es sostenida por las crecientes preocupaciones con el bienestar animal, demanda que es presentada por académicos de Medicina Veterinaria y residentes del Hospital Veterinario de la Universidad Federal de Paraná. Sumado al alto costo de modelos ya disponibles comercialmente, el objetivo del presente trabajo es presentar la confección de un modelo de bajo costo para entrenamiento de RCP en canino. Después de la adquisición de un perro de peluche, se elaboró una estructura representativa de la parte interna del tórax con un embalaje plástico de achocolatado en polvo rellenado con fibra siliconada. A continuación se produjeron los cartílagos de la laringe en goma e silicona de media flexibilidad, adheridos a una tráquea corrugada. Los moldes del paladar duro y de las arcadas dentales superior e inferior fueron confeccionados en resina, pintados con tinta acrílica y fijados a una articuladora dental modificada. Para la mucosa oral y la lengua se elaborarón estructuras de elastómero de silicona de baja viscosidad. El modelo permitió realizar los procedimientos de compresión torácica e intubación endotraqueal, etapas incluidas en la RCP. El modelo fue probado por profesionales de la Medicina Veterinaria, con experiencia en RCP, y se reportó un buen resultado. El modelo de RCP presentado permitió la simulación del soporte básico a la vida y, siendo de bajo costo, puede ser confeccionado por otras instituciones de enseñanza con este mismo propósito.

Palabras clave: compresión torácica, enseñanza, intubación endotraqueal, RCP, simulador

\section{Introdução}

A ressuscitação cardiopulmonar (RCP) deve ser iniciada imediatamente, em uma situação de parada cardiorrespiratória (PCR). A partir de cinco minutos não é possível garantir o retorno da perfusão tecidual e pressão sanguínea adequados, nem a ausência de injúrias ao sistema nervoso (Safar et al., 1990). O Reassessment Campaign on Veterinary Resuscitation (RECOVER) propõe recomendações clínicas para a aplicação de RCP em cães e gatos, visando o progresso em prognósticos positivos para estes pacientes. Nesta campanha, o suporte básico à vida inclui o reconhecimento da PCR, administração de compressões torácicas, manejo das vias aéreas e ventilação. O RECOVER considera que uma RCP eficiente demanda habilidades cognitivas e psicomotoras para realizar todos os passos indicados de 
maneira coerente e ágil. Desta maneira, o treinamento almejado deve abranger, além de componentes didáticos, prática de habilidades manuais englobando, por exemplo, o uso de simuladores e modelos discriminados (Fletcher et al., 2012).

As crescentes preocupações com o bem-estar animal, embasadas pelo conceito dos 3 "Rs" (Replacement, Reduction, Refinement), sustentam a confiabilidade de utilizar modelos e manequins sintéticos no âmbito estudantil. Esses recursos contemplam uma alternativa segura e ética ao treinamento de competências práticas (Gauthier \& Griffin, 2005; Scalese \& Issenberg, 2005). Há modelos alternativos para o exercício de diversos procedimentos, incluindo a RCP, disponíveis comercialmente. Contudo, usualmente, os valores demandam grande investimento financeiro, contexto incompatível com a realidade de muitas instituições de ensino brasileiras. A somatória do alto custo e da demanda apresentada por acadêmicos de Medicina Veterinária e residentes do Hospital Veterinário da Universidade Federal do Paraná (UFPR), exigiu a elaboração de um modelo próprio. Sendo assim, o objetivo do presente trabalho é apresentar a confecção de um modelo de baixo custo para treinamento de RCP em cão.

\section{Material e métodos}

Na elaboração do modelo de RCP buscou-se utilizar material de fácil acesso e baixo custo que trouxesse às peças confeccionadas média a alta discriminação, ou seja, resultados de consistência e mobilidade similares àquelas das estruturas representadas. A construção do modelo teve início a partir da aquisição de um cachorro de pelúcia, cujo tamanho, correspondente a um animal de porte pequeno (até $8 \mathrm{~kg}$ ), foi utilizado como referência para a confecção das partes pertinentes ao modelo. Em uma primeira etapa, as costuras da pelúcia relativas ao dorso e à rima oral do animal foram desfeitas e parte da espuma de preenchimento contida no interior da pelúcia foi removida.

Para representar o tórax, em relação a textura e rigidez, foi escolhida uma embalagem plástica de achocolatado em pó sem as suas extremidades (tampa e fundo). Esta foi preenchida com fibra siliconada (espuma de preenchimento de almofada), de modo a simular a resistência oferecida pelos músculos e órgãos da região. O molde das cartilagens da laringe foi feito manualmente, baseado em representações anatômicas da literatura disponível. As cartilagens foram inicialmente produzidas em clay para modelagem à base de argila e óleo, e a partir destes modelos foi feito molde em borracha de silicone de média flexibilidade da marca Redelease ${ }^{\circledR}$ (Figura 1). Para se obter a peça final, foi aplicada uma camada de vaselina no molde e acondicionado silicone novamente sobre este. Para construção da traqueia utilizou-se uma traqueia corrugada, a qual foi alocada no interior do conjunto que formava o tórax, e, posteriormente, aderida às cartilagens da laringe com esparadrapo (Figura 2).

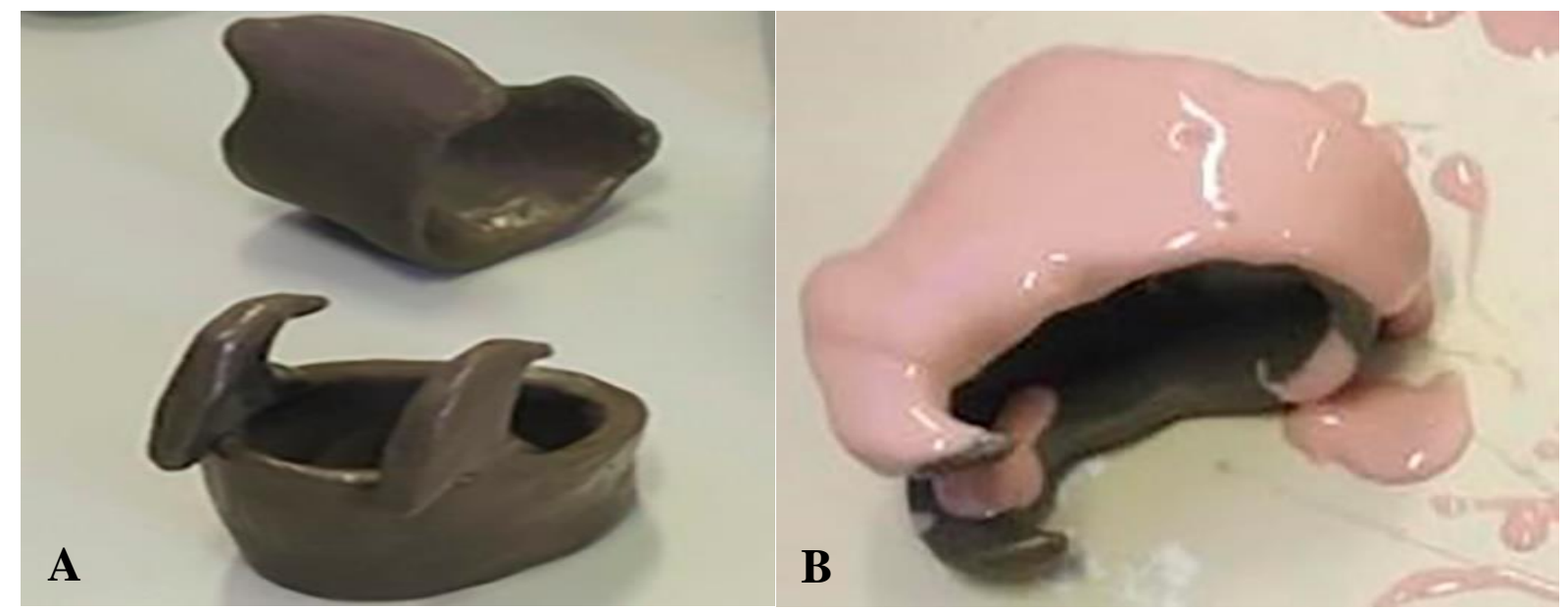

Figura 1.A. Confecção dos moldes das cartilagens da laringe com clay para modelagem. B. Aplicação da primeira camada de silicone sobre os moldes.

Os moldes do palato duro e das arcadas dentárias superior e inferior foram preparados a partir de cadáver ético de cão de porte semelhante ao da pelúcia, utilizando borracha de silicone de média flexibilidade (Redelease ${ }^{\circledR}$ ). A partir destes moldes, foram confeccionadas as peças em resina de poliester cristal de baixa viscosidade e feita sua pintura com tinta acrílica buscando a coloração próxima da real (Figura 3). 


\section{Freitag et al.}

De forma a permitir a abertura da boca, as peças referentes às arcadas dentárias superior e inferior foram fixadas a uma articuladora dental modificada, com o uso de cola instantânea (Super Bonder® Power Flex). Após essa etapa, as partes superior e inferior da peça foram coladas em um tecido, o qual foi então costurado na região correspondente a boca do boneco de pelúcia.

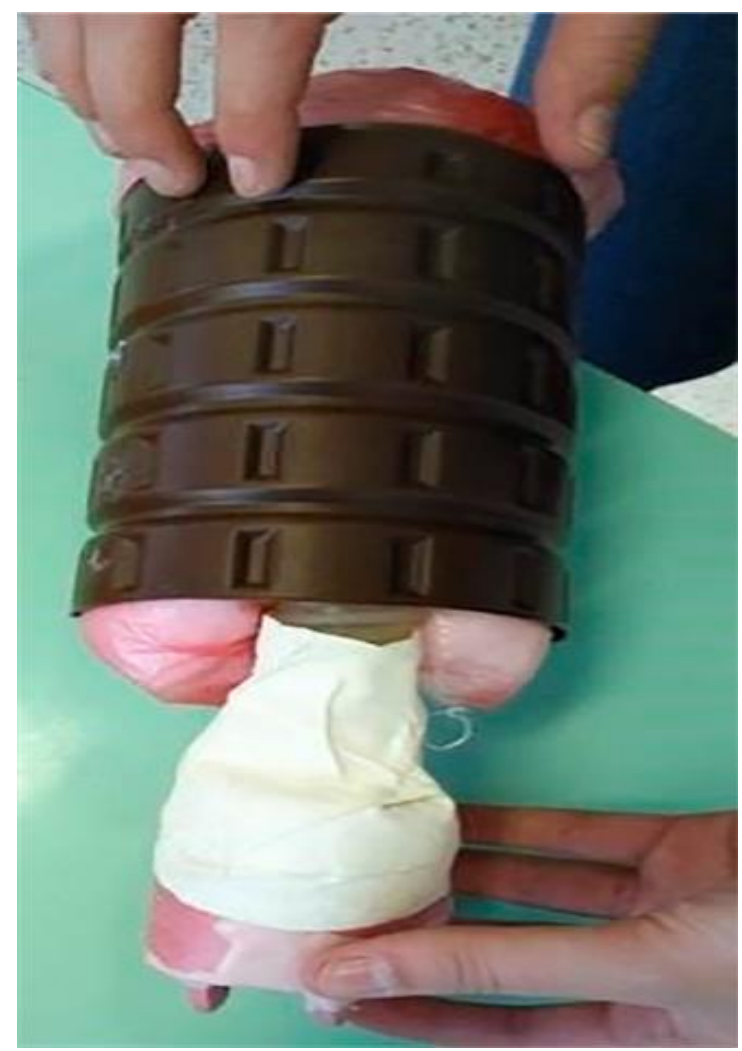

Figura 2. Conjunto representativo do tórax, traqueia e cartilagens da laringe.

Para simulação da mucosa oral ("bochechas"), foi utilizada uma camada fina, já curada, de elastômero de silicone de baixa viscosidade Ecoflex 00-30 (Smooth-on®) juntamente com corante vermelho (líquido $\mathrm{Xadrez}^{\circledR}$ ), até que a cor desejada fosse obtida. Uma parte deste material foi aderida às arcadas dentárias com o uso de cola instantânea, de modo a simular a gengiva, enquanto o restante foi colado diretamente na pelúcia na região correspondente às "bochechas".

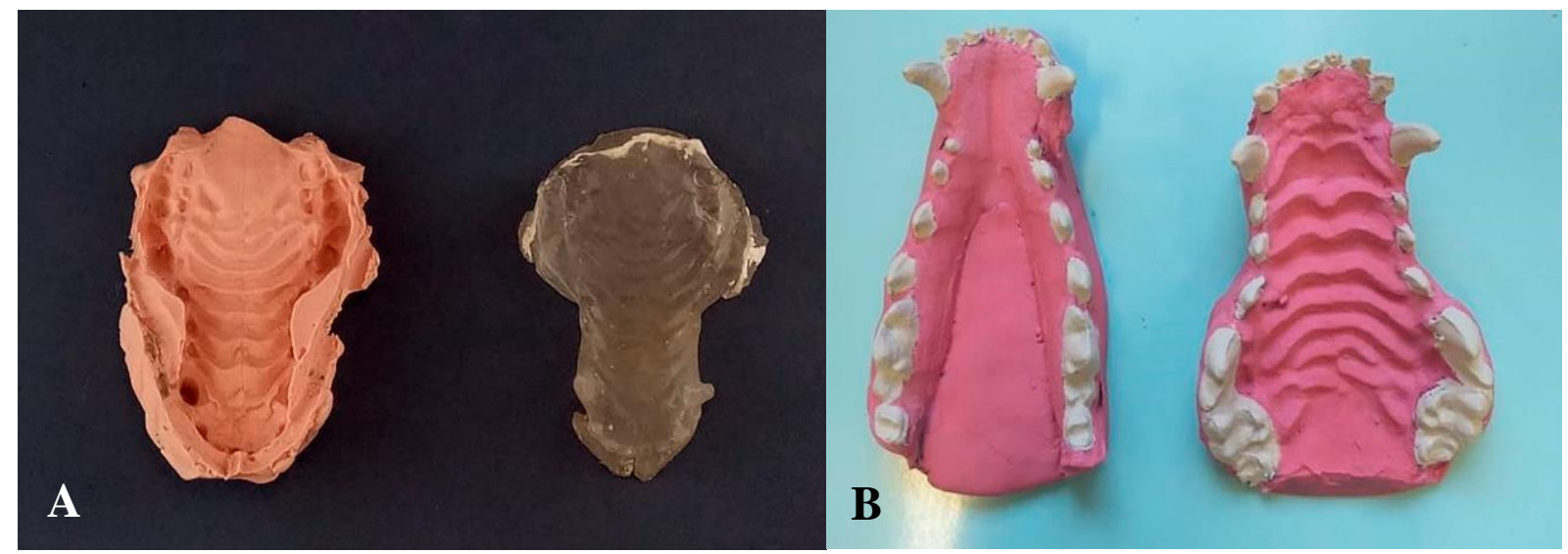

Figura 3. A. Modelo negativo do palato duro feito com silicone a partir de cadáver ético e modelo de resina. B. Modelos em resina do palato duro e das arcadas dentárias superior e inferior, já pintados.

Para a confecção da língua, primeiramente foi feito um molde de plastilina esculpido manualmente e, com base neste, um molde negativo em borracha de silicone de média flexibilidade (Redelease ${ }^{\circledR}$ ). Em seguida, foi utilizado o elastômero de silicone Ecoflex 00-30 (Smooth-on ${ }^{\circledR}$ ) com corante. Junto a 
este silicone foi colocado um tecido de malha elástica, com o objetivo de proporcionar elasticidade e durabilidade à peça final e permitir a tração durante o procedimento de intubação (Figura 4). A língua foi então inserida na boca do modelo, sendo fixada à articuladora, permitindo a visualização conferida na Figura 5 .

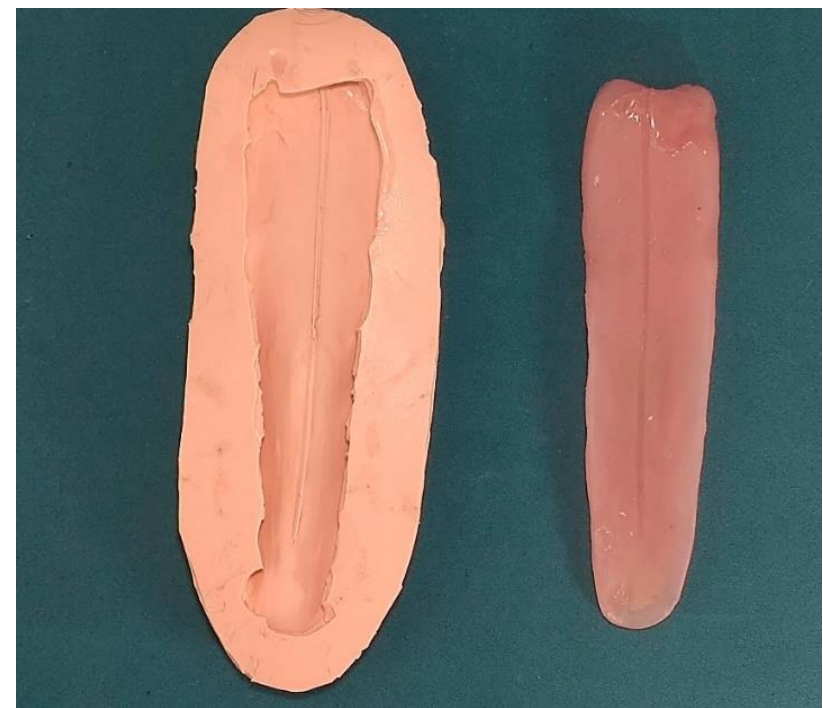

Figura 4. Molde negativo da língua feito com borracha de silicone (esquerda) e modelo final da língua em elastômero de silicone com corante (direita).

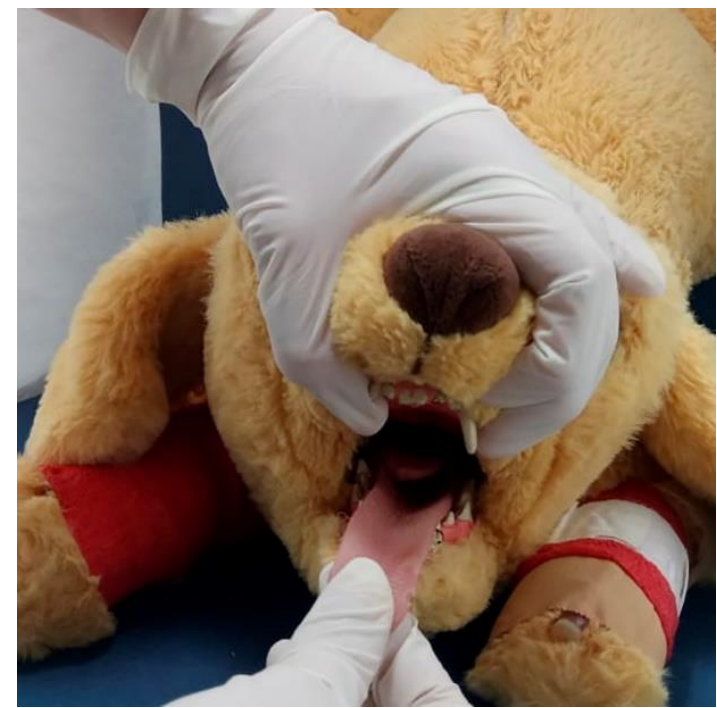

Figura 5. Modelo sintético de cão para treinamento de ressuscitação cardiopulmonar. Visualização da língua e epiglote na abertura da cavidade oral, para intubação orotraqueal.

Em seguida à montagem, foi adicionado um zíper na costura da região torácica, visando permitir a manipulação do interior do modelo quando necessário. Após a conclusão do mesmo, este foi submetido a testes práticos com médicos veterinários, para conferir sua utilidade como modelo para treinamento de RCP em cães.

\section{Resultados e discussão}

O modelo desenvolvido atingiu o objetivo de apresentar-se como uma opção de menor custo e boa discriminação para treinamento de RCP em cães. Comparativamente a outros modelos existentes no mercado, como o manequim Critical Care Jerry, cujo valor médio, considerando a cotação de dólar para 4 reais, é de 16 mil reais, (sendo 11 mil reais o valor mínimo encontrado e 23 mil reais o valor máximo), torna-se vantagem o baixo custo do modelo apresentado nesse estudo, cujo valor médio foi de 300 reais. Modelos de baixo custo para intubação endotraqueal, cateterismo urinário em cadelas e acesso vascular também foram desenvolvidos por outros autores, os quais obtiveram resultados positivos no que tange o aprendizado de habilidades necessárias para estas práticas (Aulmann et al., 2015; Ribeiro et al., 2013).

A discriminação requerida no presente modelo foi obtida pelo uso de alguns materiais, dentre eles, a embalagem de achocolatado utilizada para substituir a cavidade torácica que possuía ranhuras com textura próxima a das costelas; a espuma utilizada para preencher a embalagem de achocolatado que possuía consistência fidedigna quando um tórax é comprimido; o silicone empregado para construção da língua que forneceu a flexibilidade necessária para expor o órgão durante o procedimento de intubação endotraqueal; o material utilizado para simulação de mandíbula, que permitiu a movimentação adequada das arcadas dentárias e abertura da boca.

O modelo tem sido empregado por profissionais das áreas de Cirurgia e Anestesiologia Veterinária em cursos de emergência, nos quais também é utilizado simulador humano para a prática de RCP. Estes profissionais relataram que o uso do modelo promoveu uma melhora na veracidade do treinamento e nas condições de higiene do ambiente, uma vez que tornava possível descartar o uso de cadáver. Além disso, a discriminação e fidelidade durante a execução da massagem cardiorrespiratória e intubação endotraqueal foram destacadas como aspectos positivos por estes profissionais.

A ausência de estruturas que representem vasos sanguíneos foi apontada como sugestão de aperfeiçoamento, uma vez que o procedimento de canulação também é necessário na técnica de RCP. A 
recomendação foi acatada, posteriormente, com a fixação de uma borracha de látex, no membro torácico esquerdo, com bandagem elástica $\left(\right.$ Vetrap $\left.^{\circledR}\right)$ e um PRN na extremidade. Esse utensílio permite tanto a administração de medicamentos indicados durante a RCP, como, o aperfeiçoamento da prática de cateterismo venoso. Essa necessidade foi sustentada por dados de um estudo realizado com médicos veterinários ingressos em Programas de Residência em Medicina Veterinária no Brasil, no qual, apenas $67,3 \%$ dos respondentes declararam se considerar plenamente aptos a realizar colocação de cateter intravenoso em pequenos animais (Campos et al., 2016).

Dentre as limitações encontradas no modelo, destaca-se a falta de um cão de pelúcia com proporções semelhantes as de um cão vivo. $\mathrm{O}$ boneco de pelúcia utilizado apresentava baixa fidelidade nesse quesito, especialmente em relação às dimensões de pescoço, tórax e abdômen, sendo este um ponto passível de melhorias. Outra deficiência do modelo diz respeito a resina de poliester cristal de baixa viscosidade, utilizada para elaboração do palato duro e da arcada dentária, por ser pouco resistente para este fim, de modo que alguns dentes quebraram antes mesmo do modelo ser utilizado. Após novos testes em outros modelos, a resina de poliuretano Smooth-Cast 320 (Smooth-on) mostrou ser mais resistente, e por isso, sugerimos sua utilização, contudo seu custo é superior a primeira resina testada. Podemos ressaltar ainda que o modelo aqui apresentado permite a realização de intubação endotraqueal e compressão torácica, porém outros procedimentos podem ser necessários durante uma RCP, e tais circunstâncias devem ser incluídas em modelos futuros.

Conclui-se que o modelo aqui apresentado possui baixo custo, fácil confecção e pode ser utilizado para treinamento básico de RCP por estudantes e profissionais de medicina veterinária.

\section{Referências bibliográficas}

Aulmann, M., März, M., Burgener, I. A., Alef, M., Otto, S. \& Mülling, C. K. (2015). Development and evaluation of two canine low-fidelity simulation models. Journal of Veterinary Medical Education, 42(2):151-160.

Campos, G. M. V. D. B., Stedile, R. \& Kapilé, K. V. (2016). Autoavaliação de médicos veterinários sobre sua competência clínica ao ingressarem em programas de residência. PUBVET, 10(10):721794.

Fletcher, D. J., Boller, M., Brainard, B. M., Haskins, S. C., Hopper, K., McMichael, M. A., . . Smarick, S. D. (2012). RECOVER evidence and knowledge gap analysis on veterinary CPR. Part 7: Clinical guidelines. Journal of Veterinary Emergency and Critical Care, 22(s1):S102-S131.

Gauthier, C. \& Griffin, G. (2005). Using animals in research, testing and teaching. Revue Scientifique et Technique-Office International des Epizooties, 24(2):735.

Ribeiro, C. L., Bittencourt, C. R., Ponczek, C. A. C., Barros Filho, I. R. \& Oliveira, S. T. (2013). Confecção de Modelos artificiais de baixo custo como auxílio aprendizagem de acesso vascular em pequenos animais. Archives of Veterinary Science, 18(4):20-25.

Safar, P., Abramson, N. S., Angelos, M., Cantadore, R., Leonov, Y., Levine, R., . . Stezoski, S. W. (1990). Emergency cardiopulmonary bypass for resuscitation from prolonged cardiac arrest. The American Journal of Emergency Medicine, 8(1):55-67.

Scalese, R. J. \& Issenberg, S. B. (2005). Effective use of simulations for the teaching and acquisition of veterinary professional and clinical skills. Journal of Veterinary Medical Education, 32(4):461-467.

Recebido: 4 de junho, 2019.

Aprovado: 4 de julho, 2019.

Publicado: 1 de Agosto, 2019.

Licenciamento: Este artigo é publicado na modalidade Acesso Aberto sob a licença Creative Commons Atribuição 4.0 (CC-BY 4.0), a qual permite uso irrestrito, distribuição, reprodução em qualquer meio, desde que o autor e a fonte sejam devidamente creditados. 